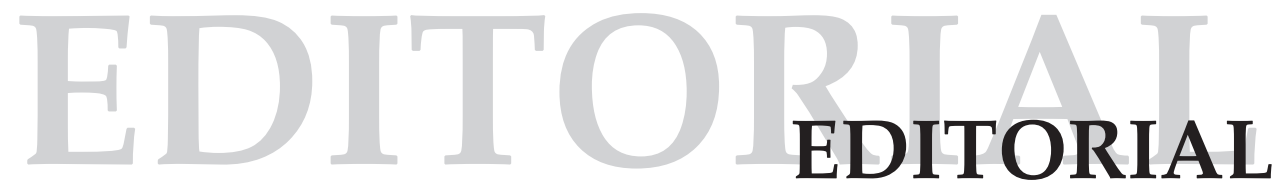

\title{
Tiempos de transición
}

La línea de sombra es una de las obras centrales del escritor polacobritánico Joseph Conrad; se trata de una novela breve escrita en plena madurez literaria y urdida con historias ancladas en las propias vivencias del autor a fines del siglo XIX. En medio de un viaje cargado de dificultades extremas (la peste diezma la tripulación, los vientos anunciados nunca llegan, el barco inmóvil es la forma que adquiere una pesadilla colectiva), un joven capitán asume riesgos y responsabilidades que el momento y las circunstancias le demandan. Como metáfora de juventud en tránsito, la línea de sombra representa la superación obligada de toda condición temerosa e inexperta; es también la batalla contra el desgano ante las exigencias del momento, así como la adopción de compromisos insoslayables que demandan los retos del presente. Pese a las dificultades de apariencia insalvable, la energía vital del capitán lo convierte en el personaje capaz de tomar el mando que hará navegar el barco hasta el puerto previsto en la ruta.

Como metáfora de la transición, la novela de Conrad pone sobre la mesa las capacidades humanas y sociales para actuar ante retos y desafíos. En una conversación al final del relato, el joven capitán y su amigo Giles reflexionan sobre lo aprendido en la experiencia: "es preciso que un hombre luche contra la mala suerte, contra sus errores, su conciencia y otras zarandajas por el estilo. Si no, ¿contra qué lucharía uno?", advierte Giles.

A la manera de las historias de viajes en barcos de vapor narradas por Conrad, los acuerdos firmados entre un sector de la insurgencia y el gobierno nacional plantean una ruta de navegación con retos inéditos para la sociedad colombiana. A esta altura del proceso de implementación los primeros balances arrojan saldos positivos con la dejación de las armas: han disminuido en forma notable los índices de criminalidad 
asociados al conflicto armado. Apelando a los conceptos acuñados por los investigadores de la paz, es probable que el mayor rédito hasta ahora haya sido la generación de paz negativa (disminución de la violencia directa). Los mayores obstáculos se encuentran en las decisiones políticas que transforman, reinterpretan y desdibujan los contenidos de lo pactado. Como lo ha advertido John Paul Lederach, la mitad de los acuerdos fracasan en su implementación; el sentido de la transición no es necesariamente optimista y constructivo.

Más de ocho millones de víctimas después el país tiene la posibilidad de crear e incorporar otras reglas de juego que permitan gestionar, regular y transformar positivamente sus conflictos sociales, económicos y políticos. La transición —quizá la expresión más acertada para denominar estos tiempos de oportunidades, incertidumbres y conflictividades emergentesno solo se refiere a los procesos de desarme y a la puesta en marcha de las políticas públicas para desplegar los acuerdos alcanzados después de un lustro de diálogos; definida de forma general, la transición hace referencia al conjunto de decisiones y acciones que potencian o inhiben las transformaciones necesarias para crear y cultivar una sociedad decente.

Las disputas actuales por la interpretación de los contenidos y los alcances de los acuerdos han desatado y exacerbado múltiples tensiones sociales, económicas, ambientales y políticas. En algunas zonas del país, la paz territorial está sometida a pruebas extremas: los actores armados buscan ampliar o consolidar los poderes locales, al mismo tiempo que ponen en marcha a sangre y fuego dispositivos de control de los recursos naturales y el dominio territorial. La caracterización y comprensión de estas dinámicas se impone como reto para la investigación y la producción académica.

Desde la década de los años 60 — con la publicación de La violencia en Colombia - la agenda de investigaciones en ciencias sociales ha estado en buena parte copada por trabajos centrados en el examen de las causas, dinámicas e impactos de las violencias directas, estructurales y simbólicas. En los tiempos que corren, a la vez que se avanza en los estudios sobre el conflicto armado y las paces, los investigadores están diversificando los trabajos y ampliando las fronteras con repertorios teóricos y metodológicos igualmente variados tal como se muestra en esta edición de la revista VIRAJES.

En una mirada panorámica al contenido de este número se encuentran reflexiones acerca de las transiciones de hoy de la sociedad colombiana: los lectores tienen la posibilidad de indagar en las nuevas identidades del pueblo Nasa de Tierradentro; examinar los cambios de la familia en el Eje Cafetero; aproximarse a la movilización colectiva de los corteros en el valle del Cauca y, con el artículo de Guillermo Villegas-Arenas y Juan Guillermo 
Villegas-Álzate, asociar la economía globalizada con los cambios que se suscitan en el complejo entramado que supone el paso de ciudad a región metropolitana. Cada uno de los autores crea otros y nuevos cauces, rupturas, alteridades o rutas paralelas a las corrientes de pensamiento imperantes.

Para quienes centran la atención en los enfoques y diseños metodológicos, Carlos Andrés Carreño (experto en conservación y restauración de bienes muebles) reflexiona sobre su propio proceso de investigación apoyado en la museología crítica; empleando metodologías participativas realiza una propuesta para asociar el museo con las comunidades "que como las campesinas requieren de referentes que fortalezcan sus vínculos socioculturales". La profesora Gretel EspinosaHerrera estudia "los comportamientos diferenciados por género y consumo de sustancias psicoativas entre universitarios", utilizando una metodología mixta. Por su parte, los investigadores Marleny Restrepo-Valencia y Arney Alfonso Vega-Martínez indagan sobre el espacio público y las demandas de los ciudadanos a través de una perspectiva metodológica cualitativa.

Los ecos del pasado en el tiempo presente se encuentran en los textos de Vladimir Montaña-Mestizo ("La regionalización de los sentimientos") y en "Antropología del barroco III", de Jesús García Ruiz.

Se incorporan al contenido de la revista los trabajos de profesores universitarios como Edgard David Serrano y Wilson Escobar Ramírez, cuyos ensayos dan cuenta de indagaciones de apariencia disímil como la economía y el teatro latinoamericano. La lectura cruzada de ambos artículos permite encontrar claves acerca de la forma cómo investigadores y creadores interpretan y ponen en escena los conflictos del desarrollo y las búsquedas de respuestas a los desafíos teóricos, de la imaginación y de la acción.

El contenido de la revista VIRAJES lo complementan la traducción de un artículo de la profesora francesa Christine Delory-Momberger, realizada por Juan Felipe Zuluaga-Molina, y la reseña del trabajo de Bárbara Miller por parte de John Arias-Hernández.

Como en la novela de Conrad, los artículos seleccionados para esta edición de VIRAJES hacen parte de la delgada línea de sombra que une el incierto tiempo presente con anuncios de otras trayectorias biográficas y con la identificación de fuerzas de cambios colectivos capaces de empujar el barco hacia otros y mejores puertos.

\section{MARIO HERNÁN LÓPEZ-BECERRA Editor invitado \\ Profesor Universidad de Caldas}

